\title{
IMPLEMENTASI PROGRAM INKLUSI KEUANGAN BTPN SYARIAH
}

\author{
Lisa Aprin Riati ${ }^{1)}$, Alvien Nur Amalia ${ }^{2)}$ \\ STIE Indonesia Banking School ${ }^{1)}$ \\ STIE Indonesia Banking School ${ }^{2)}$ \\ alvien.amalia@ibs.ac.id
}

\begin{abstract}
ABSTRAK
Program inklusi keuangan merupakan program Pemerintah dalam menjembatani masyarakat yang tidak mempunyai akses permodalan terhadap bank (unbankable). Pada umumnya masyarakat kelompok ini merupakan masyarakat miskin yang bertempat tinggal di pelosok atau pedesaan. Bank Tabungan Pensiunan Nasional (BTPN) Syariah sebagai salah satu bank umum syariah nasional mendukung program tersebut melalui inovasi dengan adanya produk Wow! IB. Produk ini melayani kebutuhan masyarakat yang selama ini belum terjangkau oleh layanan perbankan. Pada BTPN Syariah Kantor Pusat, Divisi Incubation Management dan Divisi Sale Distribution Head (SDH) II menjadi pelaksana pengembangan dan penerapan produk ini. Terdapat sejumlah permasalahan teknis di lapangan ketika pelaksanaan program inklusi keuangan ini. Salah satunya adalah human error, yaitu kurang telitinya petugas, adanya kendala bahasa serta masih terdapat nasabah yang buta huruf.
\end{abstract}

Kata kunci: Inklusi Keuangan, BTPN Syariah,

\begin{abstract}
Financial inclusion program is Indonesian Government programs that giving unbankable communities where most are poor communities in remote or rural areas to get capital access. BTPN Syariah as one of the national Islamic commercial banks supports the program through its product, Wow! IB. This product serves the community that has not been reached by banking services. The Incubation Management Division and Sale Distribution Head (SDH) Division II became the executor of the development and implementation of this product at BTPN Syariah Head Office. There are some of technical problems in the field when implementing this financial inclusion program. One of them is human errors, examples; some of the officer lack of thorough, language barriers and illiterate customers.
\end{abstract}

Kata kunci: Financial Inclusion, BTPN Syariah.

\section{PENDAHULUAN}

\subsection{Analisis Situasi}

Pembahasan mengenai konsep inklusi keuangan bukanlah suatu hal baru dalam dunia keuangan (Dangi, 2013). Reformasi dalam sektor keuangan mendorong kegiatan inklusi keuangan, sehingga kini inklusi keuangan menjadi inti dari agenda pembangunan internasional untuk membuat kebijakan dan lembaga pembangunan pada tingkat global (Ardic, Heimann, \& Mylenko, 2011). Secara global, indeks inklusi keuangan terus meningkat, hal tersebut didukung dengan adanya perkembangan teknologi seperti telepon seluler dan internet. Indeks inklusi keuangan global saat ini telah mencapai 69 persen atau 3.8 miliar orang yang kini telah memiliki akun bank (www.worldbank.org). Indonesia sebagai negara berkembang dengan jumlah populasi terbesar nomor empat didunia, pada akhir April 2018 mencatat pencapaian indeks inklusi keuangan sebesar 55 persen, angka tersebut masih kurang dari target pemerintah sebesar 75 persen pada tahun 2019 mendatang (Situmorang, 2018). Sulitnya akses untuk menjangkau daerah pelosok 
Indonesia, menjadi salah satu alasan terbesar belum meratanya pencapaian inklusi keuangan. Sehingga masih banyak masyarakat Indonesia yang tergolong nonbankable atau belum memiliki akses ke dalam sistem keuangan baik perbankan maupun non-perbankan (Hannig \& Jansen, 2010).

Indonesia menjadikan inklusi keuangan sebagai strategi nasional yang bertujuan untuk mendorong peningkatan ekonomi melalui distribusi pendapatan yang merata, penurunan tingkat kemiskinan serta stabilitas dalam sektor keuangan. Saat ini, sektor keuangan Indonesia tengah dihadapkan dengan tantangan menghadapi ketimpangan masyarakat dalam mengakses dan mendapatkan manfaat dari industri keuangan (Nugraha, 2014). Indonesia sebagai negara berkembang memiliki berbagai dinamika dalam permasahan ekonomi, ditandai dengan masih banyak masyarakatnya belum memiliki akun pada institusi keuangan (Tama, 2015). Akses keuangan merupakan masalah yang sering dihadapi oleh masyarakat menengah kebawah serta para pelaku Usaha Mikro Kecil Menengah (UMKM). Mereka sering kali mendapatkan sebutan sebagai non-banked atau non-bankable. Meskipun akses sektor keuangan penting bagi pertumbuhan ekonomi suatu negara, namun sebagian besar sektor swasta tidak bersedia untuk memberikan pembiayaan kepada daerah pelosok, hal tersebut dikarenakan tingginya biaya yang berkaitan dengan proses penilaian kredit, pemantauan kredit bahkan kurangnya agunan yang dijadikan sebagai jaminan atas pembiayaan (Mohieldin \& Rostom, 2011).
Dalam konteks perbankan, inklusi keuangan berkaitan dengan penyebaran atau edukasi mengenai kegiatan perbankan kepada kalangan masyarakat yang tergolong nonbankable (Chakravarty \& Pal, 2010). Eksistensi lembaga keuangan dalam menjalankan fungsinya sebagai lembaga intermediasi aktivitas ekonomi masyarakat, diharapkan dapat menjalankan fungsinya secara optimal hingga menjangkau masyarakat yang ada di pelosok Indonesia (Tama, 2015). Sistem perbankan tanpa kantor cabang atau lebih dikenal dengan branchless banking, menjadi salah satu cara yang dianggap dapat mengatasi permasalahan inklusi keuangan di Indonesia. Branchless banking yang dalam pelaksanaanya sangat berkaitan dengan mobile banking sebagai metode pelayanan keuangan dianggap sebagai pilihan yang tepat. Hal itu dikarena, perangkat telpon seluler telah banyak digunankan oleh masyarakat dari berbagai kalangan di Indonesia (Santoso, Kameel, \& Meera, 2015). Sehingga hal tersebut akan memudahkan masyarakat yang berada di pelosok Indonesia melakukan akses keuangan melalui ponsel mereka tanpa harus datang ke kantor cabang.

Teknologi yang saat ini telah diterapkan secara masif pada berbagai layanan perbankan seperti adanya mobile banking, diharapkan dapat mempermudah setiap aktivitas ekonomi yang dilakukan oleh masyarakat dalam kegiatan produksi, konsumsi dan investasi (Tama, 2015). PT. Bank Tabungan Nasioanal Syariah (BTPNS) pada tahun 2016 telah meluncurkan BTPN Wow! iB yang merupakan inovasi dari BTPNS dalam mendukung Layanan Keuangan 
Tanpa Kantor dalam Rangka Keuangan Inklusif (LAKU PANDAI) yang digagas oleh Otoritas Jasa Keuangan (OJK). BTPN Wow! iB adalah layanan perbankan berbasis syariah yang ditujukan bagi mass market yang memanfaatkan teknologi telepon genggam dan dibantu dengan dukungan jasa seorang agen sebagai perpanjangan tangan bank untuk meningkatkan jangkauan layanan keuangan kepada nasabah di seluruh pelosok Indonesia (www.btpn.com). Melalui BTPN Wow! iB dengan bantuan jasa agen, nasabah dapat melakukan pembukaan rekening, tarik tunai dan setor uang di sekitar tempat tinggal mereka dengan biaya yang sangat murah. Melalui BTPN Wow! iB, bank hadir untuk melayani kebutuhan masyarakat yang selama ini belum terjangkau oleh layanan perbankan.

Apabila dilihat dari perbandingan akses keuangan antara masyarakat yang tinggal di daerah perkotaan dengan masyarakat pelosok, pentingnya pemerataan akses keuangan sangatlah penting agar tidak terjadinya ketimpangan dalam melakukan akses keuangan. Berkaitan dengan target pencapaian inklusi keuangan di Indonesia sebesar 75 persen pada tahun 2019 mendatang, BTPN Wow! iB dapat memberikan konstribusi nyata dalam gerakan peningkatan inklusi keuangan di Indonesia. Berdasarkan hal tersebut, mendorong keinginan peneliti untuk melihat apakah pelaksanaan BTPN Wow! iB dilapangan telah berjalan secara efektif dan efisien oleh para agen. Terlebih lagi, sasaran nasabah mereka yang tidak terlalu mengenal kegiatan perbankan maupun institusi keuangan non-perbankan lainnya.
Program Wow! iB BTPN Syariah di Kantor Pusat, di laksanakan oleh dua divisi yaitu Divisi Incubation Management dan Divisi Sale Distribution Head (SDH) II. Secara umum tugas Divisi Incubation Management meliputi melakukan review terhadap existing program/produk btpn syariah dan melakukan improvement yang diperlukan dalam pemenuhan target bisnis, customer insight \& analytic: melakukan survey/mengumpulkan data dari nasabah dan melakukan analisa untuk pengembangan existing program/produk btpn Syariah, market intelligent: mengumpulkan informasi atas perkembangan yang terjadi di pasar (termasuk competitor), yang akan digunakan untuk pengembangan program / produk BTPN Syariah, melakukan follow up dengan pihak eksternal yang berpotensi untuk kerja sama pengembangan program / produk baru melakukan koordinasi dengan pihak-pihak internal (operation, legal, it, compliance, risk dll) dalam mengembangkan policy dan procedur terhadap program/produk yang sudah ada (existing) maupun yang akan diluncurkan, melakukan konsultasi atau pelaporan kepada regulator atas setiap produk baru yang diluncurkan dan melakukan sosialisasi kepada tim bisnis atas program atau produk baru yang diluncurkan.

Adapun fungsi Divisi Sale Distribution Head (SDH) II secara umum meliputi menjadi support dalam pencapaian target bisnis, membuat strategi untuk pencapaian target bisnis, memantau kondisi apakah strategi yang dilakukan efektif, menjadi fasilitator dalam menjalankan strategi bisnis. 


\subsection{Permasalahan Mitra}

Namun, dalam peraktiknya masih terdapat beberapa kendala seperti nomor petugas lapangan yang sulit dihubungi (Berita Acara, Surat Pernyataan, Nota dan Evaluasi) selain itu koneksi jaringan di pelosok juga buruk sehingga sangat mempengaruhi kinerja pekerja lapangan saat harus mengirimkan dokumen ataupun laporan ke Kantor Pusat BTPNS. Terkadang, terdapat beberapa ketidak lengkapan persyaratan dokumen seperti kosongnya kolom tanda tangan.

Human error menjadi salah satu alasan terjadinya kendala dalam pelaksanaan pekerjaan operasional seperti kurangnya ketelitian petugas saat mengelola dokumen. Kendala bahasa juga sangat mempengaruhi kinerja, perbedaan penggunaan bahasa menimbulkan potensi munculnya kesalah pahaman dan perdebatan yang akan memicu konflik. Kurangnya keterampilan para agen dan nasabah dalam pemanfaatan dan penggunaan teknologi terkini seperti handphone juga menjadi kendala terbesar dan petugas lapangan yang belum memahami betul bagaimana cara pengisian report progres target bisnis.

\section{METODE PELAKSANAAN}

Kegiatan ini berlangsung selam 6 bulan yaitu pada Agustus 2017 sampai dengan Januari 2016. Adapun kegiatan per bulan yang dilakukan dengan sebagai berikut:

1. Kegiatan pada Agustus 2017
a. Follow up pemenuhan dokumen persyaratan Likuiditas Agen (Berita Acara, Surat Pernyataan, Nota

dan Evaluasi) by e-mail dan by phone.

b. Follow up saldo Likuiditas Agen

c. Melakukan input dokumen Likuiditas Agen melalui exel online

d. Memastikan pembayaran motor operasional bagi petugas lapangan

2. Kegiatan pada September 2017

a. Memastikan pembayaran motor operasional bagi petugas lapangan

b. Rechecking kelengkapan dokumen Likuiditas Agen (Berita Acara, Surat Pernyataan, Nota dan Evaluasi)

c. Mapping Manager Sentra (MS) berdasarkan domisili

d. Follow up pemenuhan dokumen persyaratan Likuiditas Agen (Berita Acara, Surat Pernyataan, Nota dan Evaluasi) by e-mail dan by phone

e. Follow up saldo Likuiditas Agen

f. Rekapitulasi dokumen Likuiditas Agen (Berita Acara, Surat Pernyataan, Nota dan Evaluasi)

g. Membaca materi buku panduan aduhai

3. Kegiatan pada Oktober 2017

a. Follow up pemenuhan dokumen persyaratan Likuiditas Agen (Berita Acara, Surat Pernyataan, Nota dan Evaluasi) by e-mail dan by phone 
b. Rechecking kelengkapan dokumen Likuiditas Agen (Berita Acara, Surat Pernyataan, Nota dan Evaluasi)

c. Membuat surat tugas

d. Rekapitulasi dokumen Likuiditas Agen ((Berita Acara, Surat Pernyataan, Nota dan Evaluasi)

e. Memastikan pembayaran motor operasional bagi petugas lapangan

f. Observasi KFO Dramaga

g. Mengelola data dan membuat laporan Day In the Life Of (DILO) Project

4. Kegiatan pada November 2017

a. Membuat laporan hasil observasi

b. Memastikan pembayaran motor operasional bagi petugas lapangan

c. Follow up pemenuhan dokumen persyaratan Likuiditas Agen (Berita Acara, Surat Pernyataan, Nota dan Evaluasi) by e-mail dan by phone

d. Rekapitulasi dokumen Likuiditas Agen ((Berita Acara, Surat Pernyataan, Nota dan Evaluasi) e. Menginformasikan dan reminder para agen dan nasabah mengenai undian BTPN Wow! iB.

f. Membuat rekapitulasi hasil follow up agen dan nasabah undian BTPN Wow! iB

g. Memastikan pembayaran kost-kostan bagi petugas lapangan

5. Kegiatan pada Desember 2017

a. Menginformasikan dan reminder para agen dan nasabah mengenai undian BTPN Wow! iB

b. Membuat rekapitulasi hasil follow up agen dan nasabah undian BTPN Wow! iB

c. Observasi Wisma Tambun Selatan

d. Mengelola data dan membuat laporan DILO Project

6. Kegiatan pada Januari 2018

a. Maintenance Regional Support Officer (RSO) by email dan by phone

b. Membuat laporan dari report RSO perminggu

3. HASIL

DAN

PEMBAHASAN

Kegiatan Pada Divisi Incubation Management 
Pada Divisi Incubation

Management lebih terfokus dalam upaya pengembangan produkproduk BTPN Syariah seperti menyusun konsep produk agar dapat diterima oleh calon nasabah. Produk-produk yang berkaitan mendukung akomodasi pelayanan Wow! iB dilapangan juga disediakan wisma sebagai kantor operasional pengganti kantor cabang.

Berikut adalah fungsi dari adanya Divisi Incubation

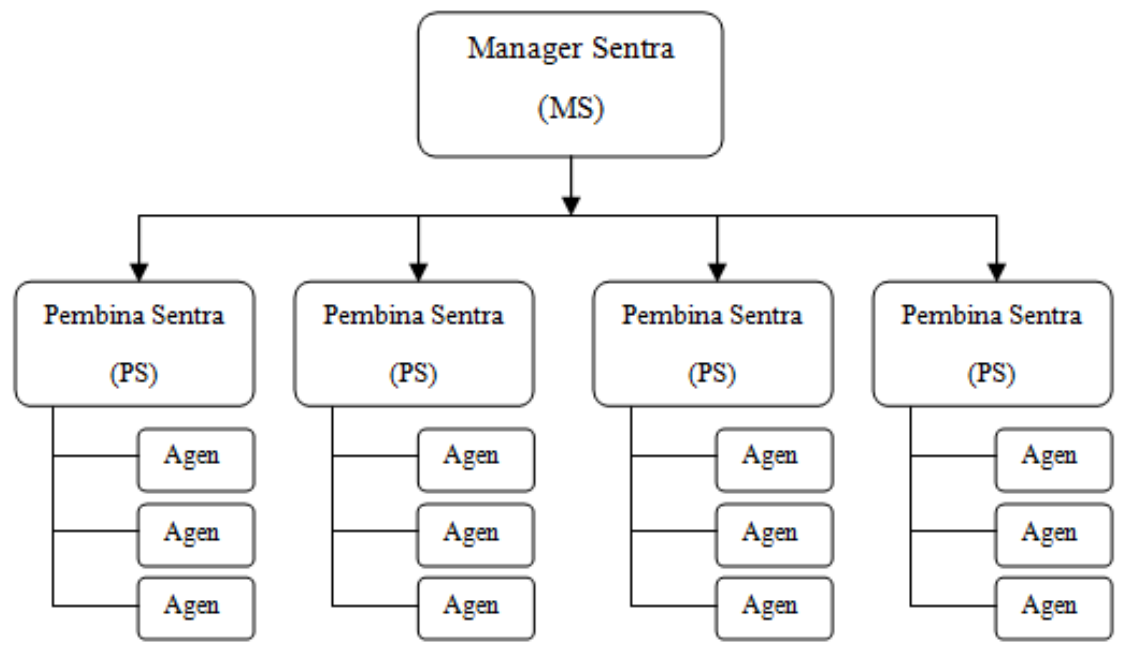

Gambar 4.1 Struktur Organsasi Pada Wisma

Sumber: Hasil Wawancara Kepala Divisi Incubation Management BTPN Syariah Kantor Pusat

dengan divisi ini ialah Paket Masa Depan (PMD) dan BTPN Wow! iB. Namun dalam pemberian tugas oleh user, lebih dominan melakukan pekerjaan yang berkaitan dengan produk Wow! iB BTPNS.

Seperti penjelasan sebelumnya pada latar belakag bahwa BTPN Syariah memiliki produk Wow! iB (program laku pandai versi BTPNS) dimana target pasarnya adalah calon nasabah menengah kebawah yang berdomisili jauh dari ibu kota atau dapat dibilang di pedesaan/daerah pinggiran ibu kota. Untuk mendukung produk Wow! iB ini, Divisi Incubation Management mendesign sedemikian rupa tahapan prosesnya. Salah satunya dengan menempatkan agen-agen BTPNS di setiap daerah. Selain itu untuk
Management bagi perusahaanialah sebagai berikut:

A. Upaya mengembangkan bisnis yang dimiliki buat perusahaan terutama dalam fungsi marketing.

B. Menganalisa hasil dari pengembangan bisnis yang diterapkan.

C. Menganalisa produk-produk dari luar untuk mengembangkan bisnis

Untuk memantau para pekerja lapangan tersebut pihak kantor pusat akan selalu melakukan Follow Up by phone maupun by e-mail guna mengetahui informasi terkini dan teraktual tentang nasabah Wow! iB. Beberapa hal yang rutin dilakukan 
dalam memantau para petugas lapangan ialah sebagai berikut:

\section{Follow Up Likuiditas Agen}

A. Follow up pemenuhan dokumen persyaratan Likuiditas Agen (Berita Acara, Surat Pernyataan, Nota dan Evaluasi) by e-mail dan by phone

Setiap kegiatan yang dilakukan oleh karyawan di masing-masing wisma mengenai aktivitas Wow! iB harus dilaporkan ke Kantor Pusat BTPN Syariah, termasuk dalam melaporkan dokumen persyaratan Likuiditas Agen. Dalam kegiatan ini dokumen yang dimaksud adalah Berita Acara pengambilan handphone, Surat Pernyataan kepemilikan rekening dan peminjaman handphone, dan Nota pembelian simcard yang dilakukan oleh karyawan BTPN Syariah untuk melakukan aktivitas Wow! iB dengan agen di daerahnya masingmasing.

Dokumen harus dipastika samapai ke kantor pusat BTPNS via e-mail, maka harus dilakukan follow up yang dilakukan by phone dan by $e$-mail guna mengingatkan para Manager Sentra (MS) untuk segera mengirimkan dokumen-dokumen tersebut.

Setelah menjalankan tugas ini selama beberapa waktu, ditemukan adanya kendala saat proses pengerjaanya yaitu:

1) Nomor Manager Sentra (MS) yang tidak dapat dihubungi (Nomor hangus, nomor tidak terdaftar, nomor tidak aktif dan nomor diluar jangkauan)

2) Maneger Sentra (MS) dan Pembina Sentra (PS) kurang memahami prosedur dan cara pemenuhan dokumen, karena untuk mengirimkan dokumen dilakukan via Share Point dimana semua dokumen harus discan terlebih dahulu.

B. Rechecking kelengkapan dokumen Likuiditas Agen (Berita Acara, Surat Pernyataan, Nota dan Evaluasi)

Setalah dokumen dikirim oleh MS ke kantor pusat BTPNS, selanjutnnya harus dilakukan rechecking atau pemeriksaan kembali apakah dokumen yang dikirim telah sesuai dengan apa yang diminta oleh kantor pusat atau tidak, memeriksa apakah semua kolom tanda tangan sudah ditanda tangani oleh pihak yang bersangkutan atau tidak dan memastikan jumlah pengambilan handphone pada dokumen Berita Acara pengambilan handphone sama dengan banyaknya nomor emai yang tercantum.Apabila hal-hal tersebut belum terpenuhi maka harus dilakukan follow up lagi untuk segera mengirimkan kembali dokumen-dokumen tersebut.

Setelah menjalankan tugas ini selama beberapa waktu, ditemukan adanya kendala saat proses pengerjaanya yaitu, pada kolom tanda tangan seringkali dikosongkan oleh MS karena pihak yang bersangkutan seperti para agen atau nasabah yang buta huruf dan tidak bisa TTD.

C. Rekapitulasi dokumen Likuiditas Agen (Berita Acara, Surat Pernyataan, Nota dan Evaluasi)

Sebelum mengirimkan laporan Likuiditas Agen harus benar-benar dipastikan tidak ada kesalahan, untuk itu harus dilakukan 
rekapitulasi dokumen Likuiditas Agen yaitu mencocokan jumlah dokumen yanng telah diupload oleh para MS di Share Point (portal yang khusus untuk menbgupload dokumen Likuiditas Agen) dengan dokumen yang telah didownload. Hal ini dilakukan agar tidak terjadi gap atau perbedaan jumlah dokumen.

Setelah menjalankan tugas ini selama beberapa waktu, ditemukan adanya kendala saat proses pengerjaanya yaitu:

1) Double upload data pada Share Point

2) Salah menempatkan attachment data pada kolom pembagian dokumen.

D. Follow up saldo Likuiditas Agen

Dalam operasional Likuiditas Agen, seorang agen membutuhkan saldo dalam rekeningnya. Untuk memenuhi kebutuhan saldo para agen dapat mendapatkannya dengan cara menghubungi Petugas Sentra (PS) dan PS dapat memenuhi kebutuhan saldo dalam rekeningnya melalui Meneger Sentra (MS). Agar tetap terpantau, setiap harinya harus dilakukan follow up mengenai saldo likuiditas agen yang dimiliki oleh Manager Sentra (MS) dan Petugas Sentra (PS) yang dilakukan by phone dan by e-mail.

Untuk pembagian saldo sendiri, pihak BTPNS selalu menyediakan saldo sebesar Rp. 3000.000 yang akan di transfer ke rekening MS dan setelah itu MS akan mentransfer saldo kepada PS sejumlah yang diminta oleh PS dengan demikian PS dapat memenuhi kebutuhan saldo Likuiditas Agen untuk para agen.

Setelah menjalankan tugas ini selama beberapa waktu, ditemukan adanya kendala saat proses pengerjaanya yaitu:

1) Saldo yang dimiliki Petugas Sentra tidak dapat memenuhi permintaan saldo para Agen.

2) Tidak adanya Pembina Sentra (cuti hamil, cuti liburan atau resign) sehingga menyulitkan agen untuk memenuhi kebutuhan saldo likuiditas agen.

E. Melakukan input dokumen Likuiditas Agen melalui exel online

Terkadang ada beberapa wisma yang terkendala dalam mengakses share point entah itu karena koneksi yang tidak mendukung atau adanya kendala dari IT BTPNS, sehingga untuk mengupload dokumen-dokumen likuiditas agen harus dilakukan oleh petugas BTPNS dikantor pusat. Biasanya bila ada kendala seperti itu para Manager Sentra (MS) akan mengirimkan dokumen-dokumen tersebut via e-mail dan petugas BTPNS kantor pusat yang akan menguploadnya ke share point.

F. Mapping Manager Sentra (MS) berdasarkan domisili

Melakukan penempatan tempat dinas para petugas lapangan terkadang dilakukan perubahan setiap periodenya. Biasanya penempatan petugas lapangan dilakukan secara random namun kadang juga penempatan dilakukan sesuai domisili.

\section{Follow Up Transformation Oficer}


A. Memastikan pembayaran motor operasional bagi petugas lapangan

Demi mendukung mobilitas para petugas lapangan dalam menjalankan tugasnya, pihak BTPNS menyediakan motor sebagai akomodasinya. Tugas follow up Transformation Officer ialah memastikan bahwa para petugas lapangan tersebut benar-benar menggunakan fasilitas yang diberikan BTPNS dan tidak disalah gunakan. Sehingga saat pembukuan pembayaran semua fasilitas tersebut dapat dipertanggung jawabkan.

B. Memastikan pembayaran kost-kostan bagi petugas lapangan

Karena kebanyakan dari petugas lapangan BTPNS bukan berasal dari daerah penempatan mereka, maka BTPNS bertanggung jawab untuk menyediakan vasillitas tempat tinggal sementara (kostkostan) bagi mereka selama dinas. Sama halnya dengan follow up mengenai kendara sebagi akomodasi, follow up kost-kostan untuk memastikan bahwa para petugas benar benar mengguanakn fasilitas tersebut, sehingga saat pembukuan pembayaran semua fasilitas tersebut dapat dipertanggung jawabkan.

\section{Pembuatan Surat Tugas}

Pembuatan surat tugas ini bertujuan sebagai pengantar dan bukti bagi para petugas lapangan bahwa mereka benar-benar ditugaskan pada daerah tersebut. Selain itu surat tugas ini juga berfungsi sebagai bukti pertanggung jawaban untuk segala fasilitas yang akan diterima para petugas lapangan tersebut.

\section{Follow Up Undian BTPN Wow! iB}

A. Menginformasikan dan reminder para agen dan nasabah mengenai undian BTPN Wow! iB, serta melakukan rekapitulasi hasil follow up

Dalam pelaksanaan tugas ini follow up dilakukan by phone kepada para agen dan nasabah Wow! iB BTPNS selain itu jumlah agen dan nasabah selalu berbeda setiap harinya dan ditentikan secara random. Undian BTPNS Wow! iB ini bertujuan sebagai penyemangat guna meningkatkan transaksi para agen dan nasabah dalam menggunakan produk BTPNS Wow! iB. Selain memberikan informasi mengenai adanya Undian BTPNS Wow! iB, penulis juga diharuskan menanyakan kendala dan keluhan dalam bertaransaksi menggunakan produk Wow! iB.

Setelah menjalankan tugas ini selama beberapa waktu, ditemukan adanya kendala saat proses pengerjaanya yaitu:

1) Kendala bahasa, karena para agen dan nasabah biasanya menggunakan bahasa daerah mereka seperti bahasa sunda, bahasa padang dll.

2) Para agen dan nasabah yang notabennya adalah ibu-ibu yang kurang memahami teknologi dan juga kurang pemahaman akan produk BTPN Wow! iB.

B. Membuat rekapitulasi hasil follow up agen dan nasabah undian BTPN Wow! iB

Setelah kita melakukan follow up terhadap agen dan nasabah Wow! 
iB, selanjutnya melakukan rekapitulasi dan pada batas waktu yaitu jam 15:00 sudah harus mengirim hasil rekapan tersebut kepada perwakilan divisi Business Suport.

\section{DILO Project}

DILO Project ini bertujuan untuk mengetahui perubahan kinerja para petugas MMS dalam kesehariannya setelah adanya program Mprospera, yaitu peralihan dari manual ke digitalisasi. Jadi apakah dengan adanya digitalisasi dengan menggubah semua hal yang tadinya dikerjakan manual dan menggunakan kertas akan berdampak pada efisiensi dan efektifitas pekerjaan para petuga MMS.

\section{A. Observasi ke KFO dan Wisma}

Pada kegiatan observasi ini penulis melakukan dua kunjungan, kunjungan pertama ialah pada KFO Dramaga yang berlokasi di Bogor. Kunjungan kedua ialah pada Wisma Tambun Selatan. Dalam kegiatan observasi, dilakukan pengamatan atas segala kegiatan operasional KFO dan Wisma serta pencatatan banyaknya waktu yang dibutuhkan untuk menyelesaikan satu tugas. Sehingga saat pengelolaan data observasi dapat dilihat seberapa efisien dan seberapa efektifnya kinerja para petugas.

B. Mengelola data dan membuat laporan DILO Project

Setelah melakukan observasi ke KFO dan Wisma, selanjutnya ialah mengelola data yang telah dikumpulkan guna membuat laporan DILO Project. Dari hasil observasi tersebut menunjukan bahwa adanya peningkatan kinerja para petugas
MMS dan hal itu juga sangat mempermudah para petugas lapangan yang tidak perlu lagi membawa kertas dalam setiap kunjungannya ke nasabah karena para petugas hanya perlu membawa tablet yang telah disediakan oleh BTPNS untuk menunjang segala kegiatan transaksi.

\section{Kegiatan Operasional Pada Divisi Sales Distribution Head (SDH) 2}

Pada divisi Sales Distribution Head (SDH) 2 lebih terfokus sebagai support bisnis agar tercapainya target-target bisnis perusahan. Untuk mencapai target bisnis yang telah ditentukan dapat dilakukan dengan cara menyediakan segala fasilitas bisnis yang dibutuhkan oleh para Regional Support Officer (RSO), setelah itu juga dilakukan pemantauan kinerja Regional Support Officer (RSO) . Berikut kegiatan yang terkait dengan divisi Sales Distribution Head (SDH) 2 .

1. Maintenance RSO by e-mail dan by phone

Tugas maintenance RSO ini bertujuan untuk memantau dan mengetahui progres dari pencapaian target petugas lapangan. Maintenance dilakukan setiang harinya by phone dan by e-mail. Dalam melakukan pekerjaan ini ditemukan beberapa kendala yang menghambat yaitu,

A. Petugas lapangan yang jarang berada di wisma karena pekerjaannya didominasi berada di luar wisma.

B. Koneksi jaringan internet yang buruk sehingga menyebabkan keterlambatan pengiriman report target bisnisnya. 
C. Beberapa petugas lapangan yang belum memahami betul bagaimana cara pengisian report progres target bisnis.

2. Membuat laporan dari repport RSO perminggu

Setelah melakukan maintenance hal yang harus dilakukan selanjutnya ialah membuat laporan dari setiap report yang telah diterima dari para $\mathrm{RSO}$ guna menilai kinerja mereka dalam pencapaian target yang telah ditetapkan. Setelah menjalankan tugas ini selama beberapa waktu, ditemukan adanya kendala saat proses pengerjaanya yaitu waktu penyelesaian report RSO perminggu bergantung pada report yang dikirimkan oleh petugas lapangan, sehingga terkadang terjadi keterlambatan penyerahan.

\section{KESIMPULAN}

Sejauh ini produk BTPN Wow! iB yang dimiliki oleh BTPNS guna memberikan konstribusi nyata dalam meningkatkan inklusi keuangan di Indonesia, telah memiliki berbagai fasilitas pendukung yang memadai agar tercapainya tujuan BTPNS. Fasilitas yang disediakan antara lain kebutuhan untuk menunjang agen BTPN Wow! iB seperti alat transportasi, tempat tinggal, smartphone, serta penunjang lainnya. Meskipun masih terdapat beberapa permasalahan dan kendala dalam pelaksanaan program tersebut.

\section{REFERENSI}

Ardic, O. P., Heimann, M., \& Mylenko, N. (2011). Access to Financial Services and the Financial Inclusion Agenda around the World A Cross-Country Analysis with a New Data Set. The World Bank Financial and Private Sector Development Consultative Group to Assist the Poor, (January), 2-55.

Chakravarty, S. R., \& Pal, R. (2010). Measuring Financial Inclusion: An Axiomatic Approach. Indira Gandhi Institute of Development Research, (March), 1-36.

Dangi, N. (2013). Current Situation of Financial Inclusion in India and Its Future Visions. International Journal of Management and Social Sciences Research (IJMSSR), 2(8), 155-166.

Hannig, A., \& Jansen, S. (2010). Financial Inclusion and Financial Stability: Current Policy Issues.

Mohieldin, M., \& Rostom, A. (2011). The Role of Islamic Finance in Enhancing Financial Inclusion in Organization of Islamic Cooperation ( OIC ) Countries. The World Bank Islamic Economics and Finance Working Group, (December), 1-59.

Mufidah, H. K. (2015). Penelitian Kualitatif Deskriptif.

Nugraha, U. (2014). Strategy to Accelerate Financial Literacy Rate in Indonesia: Best Practices from Selected Countries Strategi Kebijakan Percepatan Tingkat Literasi Keuangan di Indonesia: Studi Praktik Terbaik Beberapa Negara Terpilih. Jurnal Perencanaan Pembangunan The Indonesian Journal of Development Planning Strategy, 78-86.

Santoso, B., Kameel, A., \& Meera, M. (2015). Indonesian Community Mobile Financial Inclusion. International Review of Management and Business Research, 4(1), 223-244. 
Amaliah: Jurnal Pengabdian Kepada Masyarakat Volume 3 No. 2 November 2019

Situmorang, A. P. (2018). BI ungkap penyebab inklusi keuangan Indonesia tumbuh lambat.

Tama, C. M. (2015). Studi Financial Inclusion dan Financial Deepening di Indonesia.

www.btpn.com diakses pada Minggu, 28 Oktober 2018 pukul 12.20 WIB

www.worldbank.org yang diakses pada Selasa, 25 Oktober 2018 pukul 02.30

WIB 